Há consenso na literatura sobre a eficácia de políticas públicas voltadas para a questão dos problemas relacionados ao uso de álcool, embasadas em experiências exitosas, nacionais e internacionais, empreendidas, sobretudo, junto a populações urbanas não-indígenas. ${ }^{5}$ Sua plena efetividade, num contexto majoritariamente indígena, pode não ser amplo e similar. Entretanto, a venda de "álcool de farmácia" juntamente com bebidas alcoólicas em estabelecimentos comerciais deve ser alvo de regulamentação do poder público. Considerando-se as especificidades encontradas em municípios como SGC, conclama-se a Associação Brasileira de Psiquiatria a se aliar a outras entidades como a Sociedade Brasileira de Queimaduras e a Sociedade Brasileira de Pediatria (SBP) na discussão sobre o retorno da proibição da comercialização de álcool na forma líquida, por entender que esta temática está diretamente ligada a Saúde Mental.

Maximiliano Loiola Ponte de Souza Centro de Pesquisa Leônidas e Maria Deane, Fundação Oswaldo Cruz, Manaus (AM), Brazil

\section{Comércio de "álcool de farmácia" no município de São Gabriel da Cachoeira, Amazonas, Brasil: uma questão de saúde pública}

\author{
"Pharmacy alcohol" commerce in São \\ Gabriel da Cachoeira City, Amazonas, \\ Brazil: a question of public health
}

\footnotetext{
Sr. Editor,

A literatura especializada demonstra o impacto do consumo de bebidas alcoólicas no perfil de morbi-mortalidade da população mundial. ${ }^{1}$ A população indígena encontra-se especialmente vulnerável a estes agravos. ${ }^{2-4}$ São Gabriel da Cachoeira (SGC) é um município localizado no noroeste do Estado do Amazonas, na fronteira entre Brasil, Colômbia, e Venezuela. Estima-se que aproximadamente $90 \%$ de sua população seja composta por indígenas, pertencentes a 22 etnias diferentes. Estudo realizado em comunidades rurais, de SGC, evidenciou que o consumo de álcool líquido $96^{\circ}$ Gay-Lussac ("álcool de farmácia") faz parte das substâncias alcoólicas lá ingeridas. ${ }^{3} \mathrm{~A}$ venda de álcool etílico hidratado, em todas as graduações, e álcool etílico anidro por atacadistas e varejistas foi temporariamente suspensa no Brasil pela Resolução-RDC n 46, de 20 de fevereiro de 2002, da Agência Nacional de Vigilância Sanitária. Tal resolução visava evitar os riscos oferecidos à saúde pública decorrentes de acidentes por queimadura e de ingestão, principalmente em crianças. Destaca-se, aqui, que na área urbana de SGC o uso de "álcool de farmácia" intencional e não apenas acidental consiste em um problema de saúde pública a ser enfrentado. Neste município observa-se, inclusive, de forma recorrente, a exposição deste produto nas prateleiras onde estão as bebidas alcoólicas. Este, costumeiramente, não é colocado junto aos demais produtos supostamente de limpeza. Assim, colocar na prateleira cachaça e "álcool de farmácia", lado a lado, é rotina nos estabelecimentos comerciais de SGC. A força do hábito parece tão forte que, mesmo em situações nas quais o produto a ser vendido era álcool na forma gel, ele era igualmente exposto na prateleira de bebidas.
}

Financiamento: Número de processo individual 400904/2005-5 MCT-CNPq/MS-SCTIE-DECIT - n 38/2005.

Conflito de interesse: Inexistente

Referências

1. Meloni JN, Laranjeira R. Custo social e de saúde do consumo do álcool. Rev Bras Psiquiatr. 2004;26(Suppl. 1):7-10.

2. Kunitz SJ, Levy JE. Drinking careers: a twenty-five-year study of three Navajo populations. New Haven/London: Yale University Press; 1994.

3. Souza ML, Garnelo L. Quando, como e o que se bebe: o processo de alcoolização entre populações indígenas do alto Rio Negro, Brasil. Cad Saude Publica. 2007;23(7):1640-8.

4. Guimaraes LA, Grubtis S. Alcoolismo e violência em etnias indígenas: uma visão crítica da situação brasileira. Psicol Soc. 2007; 19(1):45-51.

5. Laranjeira R, Romano M. Consenso brasileiro sobre políticas públicas do álcool. Rev Bras Psiquiatr. 2004;26 (Suppl.1):68-77. 